\title{
Medical assistance at the sea: legal and medico-legal problems
}

\author{
Giovanna Ricci ${ }^{1}$, Isabel Pirillo ${ }^{2}$, Cristian Rinuncini ${ }^{3}$, Francesco Amenta ${ }^{2,3}$ \\ ${ }^{1}$ School of Law, Legal Medicine Section, University of Camerino, Camerino, Italy \\ ${ }^{2}$ Centre of Telemedicine and Telepharmacy, University of Camerino, Camerino, Italy \\ ${ }^{3}$ International Radiomedical Centre (C.I.R.M.), Roma, Italy
}

\begin{abstract}
Background: In case of pathologies or accidents on board which require medical intervention but lacking on-board medical or paramedical personnel, the ship's captain, or his delegate can contact a Telemedical Maritime Assistance Service (TMAS). International Maritime Organisation considers telemedicine at sea as an integral part of rescue procedures. Five key elements contribute to the delivery of good medical assistance at sea: one or more coordination and rescue centres; the TMAS; the possibility of intervention at sea; an organisation of appropriate institutions on ground and common operating procedures. This paper analyses the responsibility of the ship's captain and of the TMAS doctor in case of diseases or injuries on board in the frame of the main important international regulations.

Responsibility of the ship captain: In case of a disease or injury on board a ship, the captain must contact the TMAS as soon as possible. A captain not acting promptly and not doing whatever it is possible for the ill/injured person by consulting the TMAS or a physician and/or not following prescriptions received, could be charged for omission of responsibility. A captain underestimating a medical problem and knowing that the patient's condition could worsen, but still not consulting a medical centre for assistance, should be ready to accept the consequences of his choices. Responsibility of the physician: The doctor of TMAS has full responsibility for the diagnosis, prescription and treatment, while the ship's captain is responsible for the final decision. Regarding the medical treatment and assistance on board a ship, the TMAS doctor should pay attention not only for the diagnosis, but also for the prognosis. Telemedicine implies that the doctor should make decisions without a clinical examination, often without some additional medical examinations and by maintaining a contact with other people who are in direct contact with the patient. The physician usually has to rely on the account of colleagues of the sick seafarer as far as medical history is concerned. This may make harder to take a decision.

Conclusions: The ship's captain is guilty if he fails to contact a TMAS in case of diseases or accidents on board. Similar to a traditional relationship between a patient and a physician, the doctor consulted via telecommunication systems is also responsible for his diagnosis and treatment. However, in telemedicine the contrasts with the most basic principles of the traditional medicine are obvious. This makes the delivery of medical care of seafarers on board ships quite complicated.
\end{abstract}

(Int Marit Health 2014; 65, 4: 205-209)

Key words: telemedicine assistance on board, legal problems, captain responsibility, Telemedical Maritime Assistance Service (TMAS), TMAS doctor responsibility

\section{INTRODUCTION}

Treatment of injuries or pathologies in remote sites lacking doctors or adequately trained paramedic personnel is not an easy task. This happens for merchant ships the ma- jority of which does not carry medical or licensed paramedic personnel. In these circumstances it is necessary to rely on an ashore centre providing medical advice via telecommunication systems. This requires onboard personnel able to 
interact with a specialised centre as well as a stockpile of drugs and medical equipment/devices.

The possibility to give medical support to ships through the telecommunication systems started out after 1897 , the year in which Guglielmo Marconi developed the radiotelegraphy. For centuries, the cure of pathologies has been entrusted to the ship's captain and to his knowledge in medicine and hygiene. In the subsequent years, the first coastal radio stations were established and ships were equipped with radio allowing them to communicate with the mainland or between ships. On board of the ships, spontaneous initiatives consisted in the request of medical advice to ships with medical facilities on board (transatlantic ships or big cruise lines with passengers) or, through coastal radio operators, to medical personnel on land such as hospital doctors or family physicians [1]. Due to the lack of procedures and centres for curing ill people on board of the ships in remote locations, these activities were limited to single individual initiatives. The first initiative going from an amateur system to a permanent organisation specialised in providing medical care to seafarers dates back to 1920, when the New York Seaman Church obtained a radio license to provide medical care to sailing seafarers. This idea had considerable success and several countries subsequently organised their own radio medical services for ships [1].

Provision of medical care at a distance by non-medical personnel such as that on board, but under the guidance of health professionals providing medical advice, raises many ethical and legal issues. This paper analyses the legal and medico-legal issues that could arise during navigation in different countries and the responsibility of the ship's captain and of the physician providing medical advice through telemedicine.

\section{REGULATORY ISSUES}

The World Health Organisation has recognised the importance of telemedicine for the health of patients and established an observatory to determine the national and regional e-health development, providing to the Member States reliable information and guidelines for better practice, politics and standards of e-health [2]. In terms of maritime telemedicine (formerly called radio medical assistance) in 1958, the International Labour Organisation (ILO) [3] had already dictated the principles on which the remote medical assistance should be established. ILO recommended that each Member State should establish a free radio medical service for the ships, available at any time of the day or night, with specialist consultations available if necessary. It was also suggested that the personnel on board should have been trained to give concise and clear information to the physician for right consultations and suggestions. Finally, ILO published and updated list of all the radio stations with facilities for medical consultation [3].
The ILO convention issued in Geneva in 1987 [4] covered the topic in further detail. The preamble states that sailors should have health protection and access to medical treatments guaranteed as people working ashore. This preventive approach for the care of people on board of ships is innovative. In fact, health protection should include not only treatment of ill and injured sailors, but also preventive measures and health education programs so that sailors can play an active role in lowering the incidence of diseases during navigation. The first article of the 1987 Convention lists the medical equipment required on board ships and the training necessary for personnel in charge. Moreover, it leaves to the national laws to define the obligatory presence of a physician on board ships. The article 9 of this Convention established that all ships without physician on board should put one or more people in charge of the medical assistance as well as of medicinal products administration as a part of their normal duties. People in charge of medical assistance on board of ships should have completed a theoretical and practical medical course recognised by the competent authority.

The last revision of the Safety of Life at Sea (SOLAS) Convention I/21 [5] established that, in case of accidents on board ships, each maritime administration involved should conduct an investigation and provide all the results to the International Maritime Organisation (IMO), the Agency of the United Nations in charge of the sea problems. According to the United Nations Convention on the Law of the Sea (UNCLOS, Article 94, paragraph 7) [6], each member State should recruit highly qualified personnel for conducting investigations in case of on board accidents or accidents that could have caused loss of human lives or severe injuries to citizen of another State, severe damages to other ships or maritime disasters. UNCLOS Convention establishes a comprehensive regime of laws and ordinances of the oceans and seas governing all uses of their resources. Today the Convention is the system that deals with all matters relating to the law of the sea and has been ratified by 156 countries plus the European Union.

In 1992, the European Economic Community issued the Directive $92 / 29 /$ EEC on the minimum safety and health requirements for improved medical treatment on board vessels [7]. The Directive requires that every vessel flying its flag or registered by it always carries on board medical supplies of the type and amounts indicated and determined according to the characteristics of the voyage, the activities to be carried out during it, the nature of the cargo, and the number of workers. The Directive also indicates that a doctor should be on board of vessels with 100 or more workers and engaged on international voyages lasting more than 3 days. According to the Directive, responsibility for the management of the medical supplies on board a ship lies with the captain, who must receive special medical training. 
Training is also required for other crew members delegated by the captain to medical duties on board [7].

Another more articulated evolution addressed to a global audience is represented by a most recent 2000 recommendation issued by IMO on Medical Assistance at Sea [8]. This document has been updated by another basic document for seafarers, The Maritime Labour Convention of 2006 (MLC 2006). In April 2014, this document has been enlarged to improve the protection of abandoned seafarers and to provide financial security for compensation to seafarers and their families in case of death or disability [9].

According to the IMO circular MSC No. 960/2000, (tele) medical assistance at sea is an integral part of the search and rescue (SAR) service. This important document recognises 5 fundamental elements for a good service of medical assistance at sea: (i) one or more rescue coordination centres (RCC); (ii) the Telemedicine Assistance Service (TMAS); (iii) the possibility of intervention at sea; (iv) organisation of appropriate services on the ground and (v) common operative procedures.

The TMAS represents an important part of the system, it should be designated by the authority of the State involved and should be listed in the official documentation. Moreover, the TMAS represents, for whoever wants to use it, guarantee of competence and quality of service. The number of TMAS centres should be preferably limited [8]. It could be advantageous if the service is offered by a specialised centre covering different countries, especially if the language spoken is the same. It is not important whether the designated medical institution is public or private. What is important is that the physicians working in it are able to assist patients located in remote sites such as sailing ships and able to treat patients on board of ships [8]. This new international document represents an important milestone for all the specialised centres in the field and one more opportunity for improving the quality of service of the medical assistance at sea for the future.

The RCC is a fundamental element for the assistance system because, in case of danger for the life of seafarers, the ship's captain can receive help from it and get all the health information necessary to be in touch with the local TMAS and take the appropriate decisions [8], such as evacuation of the ship, landing of the injured, etc.

Because seafarers are highly exposed to injuries and/ or diseases $[1,10,11]$, they should receive assistance as similar as possible to that provided to people ashore [3]. Moreover, patient's disease may worsen lacking expert medical advice a physician on board a ship [12] and due to the remote and isolated location of the patient. The captain is in charge of the medical treatment but, despite of his theoretical knowledge of first aid, he is not able to treat a patient without help $[1,12]$. The recruited TMAS medical doctor has the full responsibility for the diagnosis and prescription of the treatment. The captain of the ship, on the other hand, is in charge of the patient examination, the administration of the treatment and for the final decision based on the specific case [8].

In this context, it is important to point out the experience of the Italian TMAS in charge of the medical assistance at sea: the Centro Internazionale Radio Medico (International Radio Medical Centre) (C.I.R.M.) which was established in 1935 [13]. The peculiarity of the Italian centre is that its activity is not limited only to Italian ships or to ships located near Italy. C.I.R.M. offers its services to all the ships without distinction of flag and in all the seas of the world [13]. C.I.R.M. today represents the TMAS service with the largest experience worldwide having assisted in the almost 80 years of its activity approximately 70,000 patients with about 800,000 medical tele-consultations.

\section{RESPONSIBILITY OF THE SHIP'S CAPTAIN}

The responsibility of the ship's captain in consulting the TMAS service is now analysed.

The Italian navigation code is detailed in regard to the responsibilities of the ship's captain. The captain of the ship is a judicial police officer and has the responsibility for the crew and the goods. In case of a health problem of a person on board of a ship, the captain should contact the TMAS as soon as possible. If this will be not the case and the patient was harmed, the captain would incur in culpable responsibility. This is a generic fault for imprudence or negligence. The strictness of the Italian regulation regarding the navigation is also based on specific fault due to inobservance of laws, rules, and disciplines. In fact, the law No. 271 of the 27 July, 1999 (article 24), in the paragraph 3 specifies that "in case of necessity, the ship's captain can ask for medical advice, via radio, to the nearest ship with a physician on board, to the C.I.R.M., or to a coastal radio station providing medical assistance" [14]. This is one of the powers of the captain and the omission of it becomes a specific fault.

Other countries, that follow the IMO circular MSC No. $960 / 2000$, behave in similar ways. In France according to the Assistance Médicale en Mer regulation [15], the ship's captain should contact a TMAS and reassure the patient of the possibility to consult a physician via radio. In Norway, the first officer is in charge of giving the medical treatment on board ships. However, the captain of the ship has the last responsibility of contacting a TMAS [3, 8].

Taking into account that the captain or any other crew member of the ship is not the right person for establishing the clinical diagnosis of a patient, if he fails to contact TMAS service, it is not acceptable that the captain of the ship is not held responsible for the consequences of his action. The 
violation of the rule of precautionary measure that characterises the criminal negligence needs to be contextualised within the typicality of a crime. This means that there is not a precautionary measure valid for all the cases, but it should consider the specific felony. The precautionary rule is definite in relation to the negative consequences intended to avoid [16, 17].

Basically, the ship's captain can be responsible for the damage of the patient and therefore for culpable omission when there are three elements: the culpable responsibility, voluntary and conscious action, the detrimental and dangerous episode, and the avoidable episode. If the captain of the ship did not act promptly and did not do whatever it was possible and required to rescue the injured, such as consulting a TMAS centre or the physician, he could be charged for omission responsibility, both generic and specific fault. The captain that underestimates an injury or a pathology, knowing that the patient could worsen, and does not consult a medical centre for assistance, accepts the risk of his inaction.

In conclusion, all the elements of the negligence are present if there is omission of request for assistance to a TMAS, and the possible consequences must be evaluated legally in the light of negligent behaviour. Moreover, it is believed that it is not possible to establish a scale of values to determine the danger of the morbid and accidental episodes. Such an attempt would imply the knowledge of the person who should use the technical elements, in other words the physicians, and contextualising this argument in a culpable responsibility of negligence. This responsibility can be considered only when it is the case to judge a culpable conduct of a not violator specialised person. Thus, with the exclusion of the possibility to determine the specific cases in which is necessary to ask for advice to a TMAS, the situation above mentioned is for all the medical conditions, and the conduct of the captain can be considered cautious anytime a member of the crew is in a condition of physical or mental impairment.

\section{THE RESPONSIBILITY OF THE PHYSICIAN}

The responsibility of the physician in case of malpractice at the sea is analysed in this section. This responsibility may vary according to regional laws and practices.

In the United States and in the majority of the Anglo-Saxon countries, the responsibility for medical malpractice at the sea is a culpable responsibility. In continental Europe countries there is a similar legal regime $[18,19]$. Physicians have created mediation organisations (institutions with expert people or offices with extra-judicial experts) that express their opinion on suspected malpractice and sometimes they can determine the amount of the indemnity. In case of disagreement, the parties have the right to appeal to an ordinary court. In Scandinavia all the professionals physicians need to stipulate an insurance in case of harm to patients. The victim does not need to demonstrate any possible error of the professional, but simply that there was a causal link between the medical act and the harm suffered [18-21].

Regarding the medical treatment and assistance on board of the ship or in remote locations, when the physician has been asked to give a consultation, the TMAS doctor, needs to pay attention to the possible diagnosis that could put the life and health of the sailors in jeopardy. Because he is in charge of the health issues on board a ship and the evacuation of the passengers [22, 23], the TMAS doctor is not only responsible for the diagnosis, but also for the prognosis. Moreover, telemedicine implies that the doctor may make decisions without a clinical examination and with or without some additional medical examinations. Due to the professionals involved, such as mediators, translators, caregivers, who have access to the dialogue between patient and physician, it can be even harder to take a decision [24, 25].

Regarding the information to the patient and obtaining his informed consent, the telemedicine service should not be used without the informed consent of the patient on board of the ship and the patient on board should be capable of choosing a doctor for consultation. This good medical practice principle is in general poorly followed on board ships as the captain chooses whether to ask for medical advice and what TMAS to call. Still, hardly ever do the patient and doctor converse directly.

When several physicians are involved in the treatment of a patient all of them are deemed to be responsible for what they do. However, the leader of the physician's team is responsible for the mistakes done by the members of his group because there is no binding contract between the doctor of telemedicine and sailors [24]. According to the telemedicine good practices, the dialogues between the physicians should be signed, copied and saved in the medical records. These documents are public acts of privileged status and have a fundamental role in searching for a responsible in a medical error [25].

Other problems for a physician could be a bad functioning of telemedical devices eventually present on board or the telecommunication system used (telephone, fax, e-mail) [25]. Moreover, he needs to have familiarity with the continuing technological development in the area and be able to use the instruments of telemedicine. Lastly, because the English language is the official language used by the radio stations, research, rescue centres, and port centres, another important thing is the mastery of the English language for communicating with the ship crew of various nationalities [25].

In terms of applicable law and competent forum involving responsibility of the ship's captain, TMAS or doctor of 
TMAS, the matter is regulated by national laws, EU Regulation No. 1177/2010 and SOLAS Regulations. For any dispute, the Court having exclusive competence will be the one of the applicant's choice, place of residence or address of the defendant.

\section{CONCLUSIONS}

Inevitably, the sea has always been a place with a high rate of accidents and the situation remains the same even today. The IMO Secretary General announced that the goal of this organisation is to reduce the number of people killed at the sea by the year 2015 and to bring the level of accidents at the sea equal to $0 . \operatorname{In} 2012$, over 1,000 deaths were recorded onboard, including accidents during international shipping, on national ferries, in developing countries and deaths in fisheries.

Telemedicine is a great innovation and may represent a very useful tool when there is no physician on board of a ship. According to the above analysis, the ship's captain is guilty if he omits to contact a TMAS in case of ill or injured people on board. If he demonstrates that it was not necessary to contact the TMAS, the captain can incur in the indemnity based on the most recent effective analysed guidelines. Alike a common relationship between a patient and a physician, the doctor consulted via telecommunication systems is also responsible for his work. However, in telemedicine this contrasts with the most basic principles of the traditional medicine are obvious [8,22], especially the physician-patient relationship, the responsibility of the physician, the maintenance of the professional secrecy, and the confidentiality and privacy of the information regarding the patient.

In telemedicine, the cases of medical responsibility are not yet defined and, because it is a new practice, currently there is not much legislation/experience about it. However, we can assert that the general principles of the right and ethical medicine can and need to be applicable. In conclusion, telemedicine is becoming an important part of the maritime medicine and will be a future challenge for all the professionals involved in delivering high quality health treatments in remote locations and hazardous conditions.

\section{REFERENCES}

1. Goethe WHG. Medical care on ships without a doctor. Radio medical advice. In: Goethe WHG, Watson EN, Jones DT eds. Handbook of Nautical Medicine, Springer, Berlin, 1984, pp. 53-65.

2. World Health Organization (WHO). Telemedicine Opportunities and Developments in Member States. Global Observatory for eHealth series, Vol. 2, Geneva, 2009.

3. International Labour Organization (ILO). Medical Advice at Sea Recommendation No. 106. Geneva, 1958.

4. International Labour Organization (ILO). Health Protection and Medical Care (Seafarers) Convention No. 164. Geneva, 1987.
5. Intergovernative-Maritime Consultive Organization. The International Convention for the Safety of Life at Sea (SOLAS), London 1975.

6. United Nations. Ocean and Laws of the Sea. United Nations Convention on the Law of the Sea (UNCLOS) of 10 December 1982. New York, 1982.

7. European Economic Community. Directive 92/29/EEC. Medical treatment on board vessels. Brussels, 1992.

8. International Maritime Organization (IMO). Medical Assistance at Sea. Circular MSC/Circ.960. IMO, London, 2000.

9. International Labour Organization (ILO). Maritime Labour Convention 2006. Geneva, 94th ILC session, 23 Feb 2006.

10. Alves PM, Leigh R, Bartos G, Mody R, Gholson L, Nerwich N. Cardiovascular events on board commercial maritime vessels: a two-year review. Int Marit Health 2010; 62: 137-142.

11. Grappasonni I, Petrelli F, Amenta F, Deaths on board ships assisted by the Centro Internazionale Radio Medico in the last 25 years. Travel Med Infect Dis 2012; 10: 186-191.

12. Dahl E. Wound infections on board ship-prevention, pathogens, and treatment. Int Marit Health 2011; 62: 186-190.

13. Amenta F, Dauri A, Rizzo N. Organization and activities of the International Radio Medical Centre (CIRM). J Telemed Telecare 1996; 2: $125-131$.

14. Decreto Legislativo 27 Luglio 1999, N. 271. Adeguamento della normativa sulla sicurezza e salute dei lavoratori marittimi a bordo delle navi mercantili da pesca nazionali, a norma della legge 31 dicembre 1998, n. 485. Italian Official Journal No. 85 of 9 August 1999, Suppl, 151 (Italian).

15. Pujos M, Duguet A-M, Ducasse J-L. Responsabilité des soins médicaux à bord des navires. Available at: http://www.developpement-durable.gouv.fr/IMG/spipdgmt/pdf/pujos_cle27c85e-2.pdf.

16. Fiandaca G, Musco E. Diritto Penale, Parte Generale. III Ed., Zanichelli, Milan, 2001 (Italian).

17. Garofoli R. Manuale di Diritto Penale, Giuffré, Milan, 2006 (Italian).

18. Loddé B. The legal aspect. Liability/Insurance. Textbook of Maritime Medicine, $2^{\text {nd }}$ Ed. Norwegian Centre for Maritime Medicine, 2013. Section Professional and Scientific. Available at: http://textbook. ncmm.no/.

19. Isac P. Les Assureurs de responsabilité in Rogier A. La Responsabilité Médicale: La Référence Pour Les Hôpitaux - Medicien - Juristes. Eska, Paris, 2005.

20. Hureau J. Les aspects nouveaux de la responsabilité médicale. La relation médecin-malade face aux enjeux de la médecine. Grao Editions, Prades, 2001.

21. Stanberry B. Legal and ethical aspects of telemedicine. J Telemed Telecare 2006; 12: 166-172.

22. Loddé B. The maritime physician. Ethical aspects. Textbook of Maritime Medicine. $2^{\text {nd }}$ Ed. Norwegian Centre for Maritime Medicine, 2013. Section Professional and Scientific. Available at: http:// textbook.ncmm.no/.

23. Jegaden D. The role of maritime physician. Textbook of Maritime Medicine, $2^{\text {nd }}$ Ed. Norwegian Centre for Maritime Medicine, 2013. Section Professional and Scientific. Available at: http://textbook. ncmm.no/.

24. Rikken B., Viruly L, Brandal L, Puskappeleit M, Schreiner A. Elements of medical care: legislation, problems. Textbook of Maritime Medicine. $1^{\text {st }}$ Ed. Norwegian Centre for Maritime Medicine, 2010. Section Elements of Maritime Medicine. Available at: http://textbook.ncmm.no/.

25. Rikken B, Viruly L, Brandal L, Puskappeleit M, Schreiner A. Telemedical advice-Telemedical assistance services TMAS. Available at: http://textbook.ncmm.no/. 